VUK BOGDANOVIĆ, Ph.D. ${ }^{1}$

E-mail: vuk@uns.ac.rs NENAD RUŠKIĆ, Ph.D. ${ }^{1}$

(Corresponding author)

E-mail: nruskic@uns.ac.rs

VALENTINA BASARIĆ, Ph.D. ${ }^{1}$

E-mail: plast@uns.ac.rs

ILIJA TANACKOV, Ph.D. 1

E-mail: ilijat@uns.ac.rs

${ }^{1}$ University of Novi Sad, Faculty of Technical Sciences

Department of Traffic Engineering

Trg Dositeja Obradovića 6, 21000 Novi Sad, Serbia
Traffic Engineering

Preliminary Communication

Submitted: 22 Dec. 2016

Accepted: 3 July 2017

\title{
CAPACITY ANALYSIS PROCEDURE FOR FOUR-LEG NON-STANDARD UNSIGNALISED INTERSECTIONS
}

\begin{abstract}
Procedures for capacity analysis of two-way stop controlled (TWSC) appeared in scientific literature in the 1970 s. In addition to standard TWSC intersections, there are also non-standard unsignalised intersections. The main characteristic of these intersections is that two major approaches are not placed opposite, but next to each other. Because of the non-standard layout of the major and minor approaches, there are unique major and minor movements at these intersections. For these movements, standard procedures for capacity analysis of standard TWSC intersections cannot be used. This paper describes a procedure for capacity analysis of non-standard unsignalised intersections with a new model for rank distribution for all major and minor movements, as well as the conflict flow calculation, and the procedure for the calculation of potential and movement capacity, according to the non-standard layout of the major and minor approaches.
\end{abstract}

\section{KEY WORDS}

capacity; priority; gap acceptance; conflict flow; level of service;

\section{INTRODUCTION}

Unsignalised intersections with a STOP or YIELD sign at minor approaches, or using general traffic rules, are called Two-Way Stop Controlled intersections (or TWSC). These intersections are very common in street and road networks in all states in the world, whereby 3-leg or 4-leg intersections with standard layout of approaches are most prevalent.

In addition to standard 4-leg TWSC intersections, there are also non-standard 4-leg TWSC intersections with two adjacent major approaches (layout - major-major-minor-minor). Furthermore, all non-standard unsignalised intersections where traffic is controlled using traffic signs will be called NSUI (Non-Standard Unsignalised Intersection).
NSUI is common in almost all European countries. Outside of Europe, there are also specific intersections (called atypical or non-standard) in the USA [1, 2] and Australia [3].

NSUI exists in every part of the street and road network where the major road bends in the centre of the intersection, which is mainly defined as "bends left or right to the adjacent approach". In previous research [4] it was shown that NSUI in some cases can be an optimal solution for traffic regulation, and that any change in the order of the major and minor roads could make the level of service (LOS) worse.

The Harders' equation for capacity calculation proposed for standard TWSC in the HCM2010 [6] can be used for NSUI. This claim is based on the fact that every standard TWSC intersection can become non-standard by changing the position of a STOP or YIELD sign, or vice versa. In addition, the fact that the equation for capacity calculation can be applied at NSUI is the only similarity between these two types of intersections.

Major and minor approaches layout at NSUI is significantly different from a standard TWSC intersection with the same geometry. The major road at NSUI bends, which makes the major and minor movements at these intersections unique, with very specific conflict flows. For that reason, ranks at NSUI cannot be the same as at standard TWSC. So, capacity calculation procedure for standard TWSC cannot be applied to NSUI.

This paper shows the full procedure for capacity and LOS analysis of 4-leg NSUI with symmetric approaches. Other types of NSUI are not considered.

\section{DEFINITION OF NON-STANDARD TWSC INTERSECTIONS}

The main characteristic of NSUI is that the major road bends in the centre of the intersection, which means that the major road is in one direction before 
the centre of the intersection, but in another after passing the centre of the intersection.

Figure 1 and Figure 2 show the same intersection with different positions of STOP signs. In one case, the intersection is standard, but in the other case, it is non-standard.

As it was shown in previous figures, the term "non-standard" is mainly related to the major/minor approach layout, but not to the geometric design of the intersection. So, by changing the position of just one traffic sign, a standard intersection can become non-standard, or vice versa.

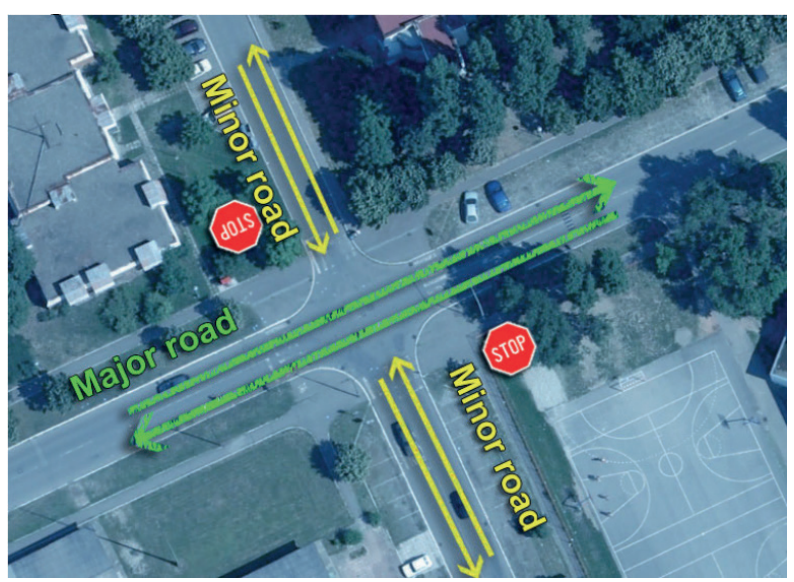

Figure 1 - Standard TWSC intersection

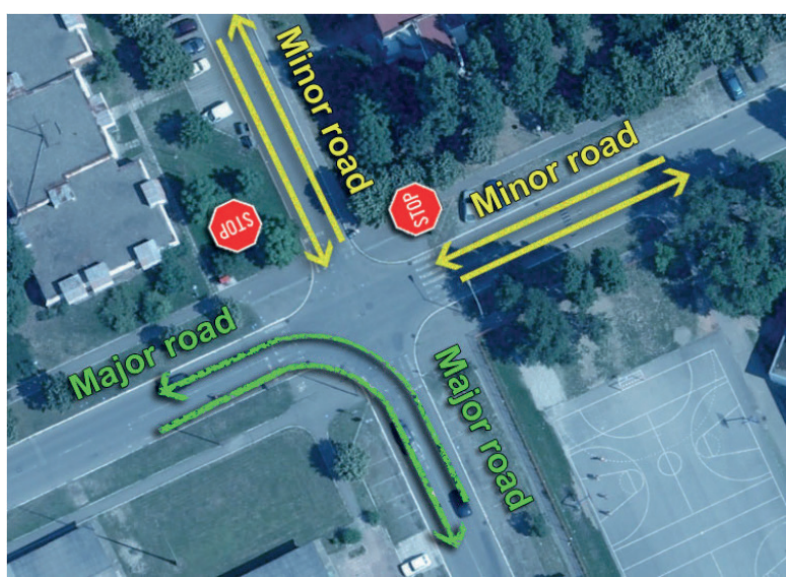

Figure 2 - Non-standard TWSC intersection

The second main characteristic of NSUI is that two major approaches are adjacent, as shown in Figure 2, which differs from the standard layout (one major approach opposite the other) as shown in Figure 1.

In order to define the direction of the major road at NSUI, and to help drivers recognize these intersections, there are specific traffic signs and specific sign combinations for NSUI $[9,10,2,11]$

The most common sign combinations in the European countries are shown in Figure 3. The sign under signs STOP, YIELD and PRIORITY ROAD is the sign that shows the direction of the bend of the major road.

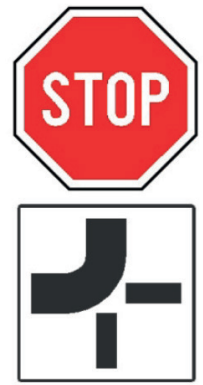

a)

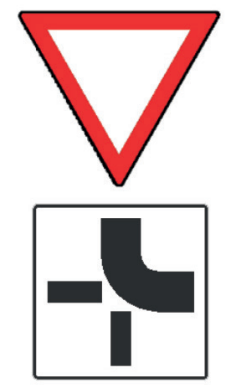

b)

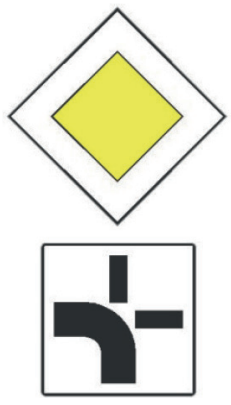

c)
Figure 3 - The most common European traffic sign combinations for NSUI

\section{RESEARCH BACKGROUND}

Capacity and traffic conditions at TWSC intersections have been the subject of numerous research studies [20, 21, 22, 23, 27], as well as drivers' behaviour at unsignalised intersection [24, 25, 26]. The first model for capacity calculation of unsignalised intersections was developed in 1965 [12]. This model was based on intervals allowing vehicles from a minor flow to enter the major flow. The procedure for capacity analysis in the first version of HCM1965 [13] makes a difference between STOP controlled and YIELD controlled intersections (AWSC or TWSC). That model analyses the capacity of an intersection with more than one traffic lane in one direction. According to HCM1985 [14], the model for capacity analysis of TWSC intersections means a separate calculation of capacity for every movement. The level of service is determined according to capacity reserve and expected delays, which was described without clearly measurable limits (described as - no delays, short delays, medium delays, long delays and congestion)

HCM1994 gives a procedure for capacity analysis at TWSC intersections where capacity is calculated separately for all movements at minor approaches (left, through, right) and left turn from major approaches [15]. That procedure is based on the gap acceptance model, which was developed in Germany [8].

$\mathrm{HCM} 2000$ and HCM2010 have the same procedure for capacity analysis, which is also based on the gap acceptance model. These procedures differ slightly from HCM1994. This procedure has a different equation for capacity calculation - Harders' equation [7], and it is also based on separate capacity calculation of all minor approaches, and left turn on major approaches. The capacity is calculated according to the given or measured headways (critical headway and follow-up headway) and conflict flow volumes. This procedure is applicable at standard unsignalised intersections where the main and minor roads are straight, and they cross at approximately 90 degrees. 
None of those procedures can be applied at NSUI. Moreover, there is no recommendation in any literature for capacity analysis of non-standard unsignalised intersections.

One of the rare research studies of NSUI was conducted by Gattis and Low [16]. The intersection layout is given in Figure 4, which shows that flows at the intersection are not labelled according to HCM flow labels. Also, the way of defining the major and minor approaches is unusual for the European conditions.

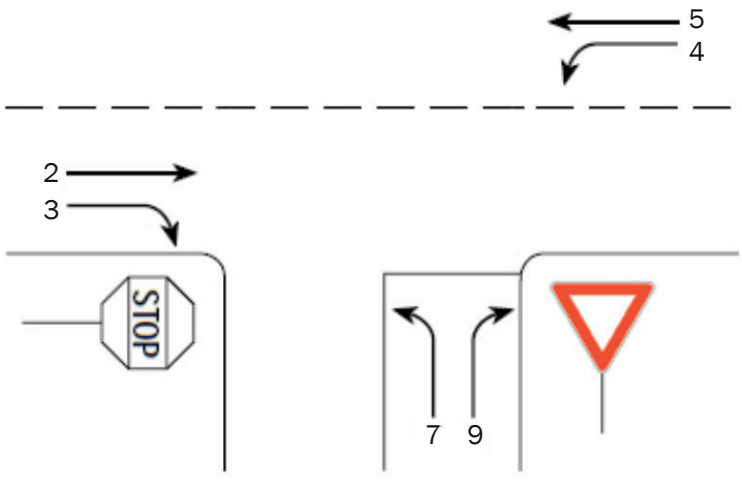

Figure 4 - Intersection layout and major/minor flow labels in Gattis and Low research

Figure 4 shows movements which are major (flow 4) or minor (flows 2 and 3) at NSUI, but different from a standard TWSC intersection (flow 4 is minor; flows 2 and 3 are major). One of the main results of Gattis and Low's research was that the values of critical headways shown in Table 1 were not measured according to the procedures proposed in HCM2000/HCM2010.

Table 1 - Gattis and Low research results

\begin{tabular}{||l|c||}
\hline \multicolumn{1}{|c|}{ Vehicle movement } & Critical headway $t_{c},[\mathrm{~s}]$ \\
\hline \hline $\begin{array}{l}\text { Through traffic from Westbound } \\
\text { (movement 5) }\end{array}$ & 3.3 \\
\hline $\begin{array}{l}\text { Left turn from Westbound } \\
\text { (movement 4) }\end{array}$ & 6.0 \\
\hline $\begin{array}{l}\text { Right turn from Northbound } \\
\text { (movement 9) }\end{array}$ & 7.8 \\
\hline $\begin{array}{l}\text { Left turn from Westbound } \\
\text { (movement 4) }\end{array}$ & 6.6 \\
\hline
\end{tabular}

Despite the fact that the measurement of the critical headways was not made according to HCM2000/ HCM2010, preliminary results show that the values of gaps at NSUI are significantly different from these values at standard TWSC intersections.

Our previous research [4] provided the basic guidelines and preliminary values of parameters for capacity and LOS analysis at 3-leg NSUI.

\section{METHODOLOGY FOR CAPACITY ANALYSIS OF FOUR-LEG NON-STANDARD UNSIGNALISED INTERSECTIONS}

Capacity analysis procedure shown in this paper is related to symmetric 4-leg NSUI, where the major and a minor roads cross at 90 degrees. These intersections are the most common of all intersections in street and road network.

Figure 5 shows a standard TWSC intersection where the main road goes straight from the approach 1 (flows 1-2-3) towards the approach 3 (flows 4-5-6). Any standard TWSC can be marked in this way.

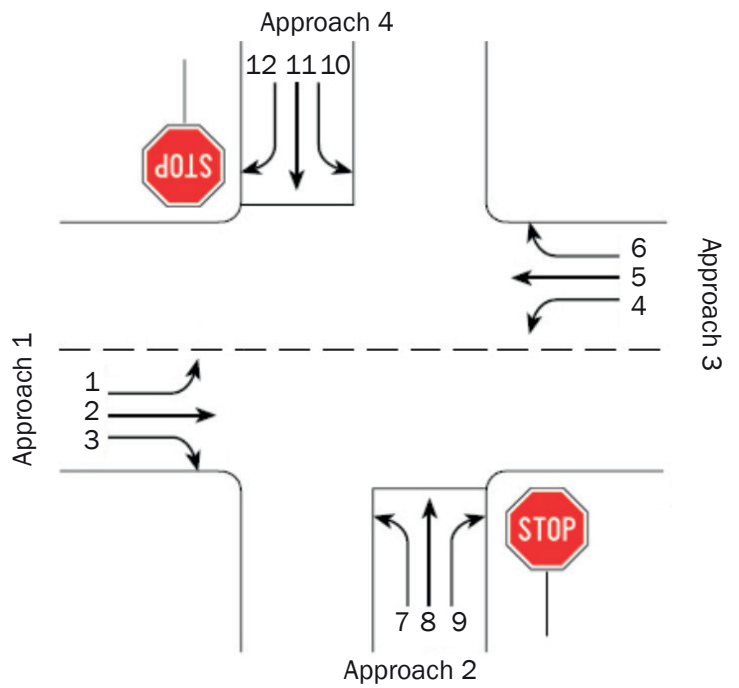

Figure 5 - Movements and approaches at standard 4-leg TWSC intersection

Figure 6 shows a non-standard TWSC intersection with 4 approaches, where the main road bends from approach 3 towards approach 2 .

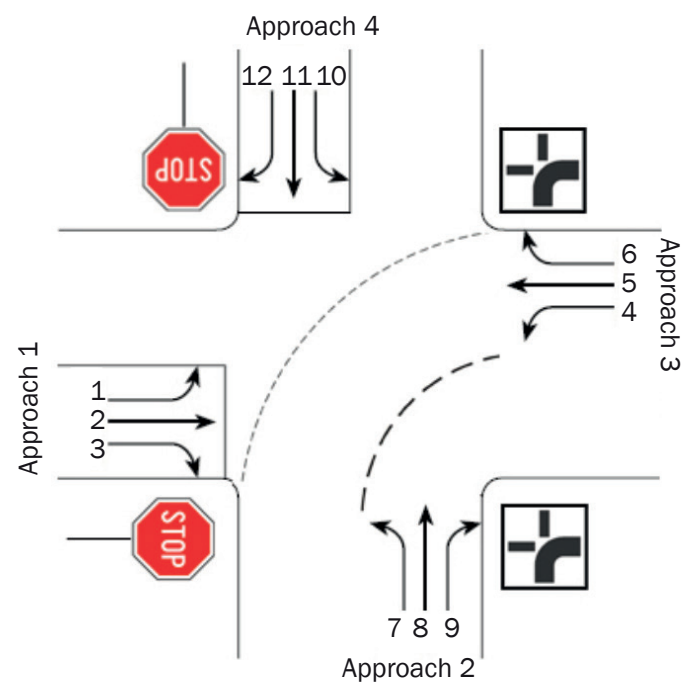

Figure 6 - Movements and approaches at non-standard 4-leg TWSC intersection 
Any non-standard TWSC intersection can be analysed according to movements in Figure 6. Before the analysis, the intersection should be rotated to the left or to the right to fit the layout given in Figure 6 [17]. Traffic flows at NSUI are labelled in the same way as at standard TWSC intersection (according to HCM2010, numbered from 1-12).

\subsection{Major and minor flows on 4-leg non-standard TWSC intersections}

Because of a different layout of the major and minor approaches, ranking of traffic flows at NSUI is significantly different from a standard TWSC intersection. Regarding the fact that two major approaches are next to each other, it can be concluded that NSUI has more minor movements than a standard TWSC intersection.

Analysing the priorities and the position of traffic signs STOP and YIELD, as well as general traffic rules, it can be concluded that at NSUI there are 12 movements, out of which 8 are minor. All movements are classified in 4 ranks regarding their character and priority.

According to the analysis of potential conflicts, ranks have been defined for a 4-leg non-standard TWSC intersection, shown in Table 2.

Table 2 - Ranks at NSUI

\begin{tabular}{|c|l|c|}
\hline $\begin{array}{c}\text { Move- } \\
\text { ment } \\
\text { number }\end{array}$ & \multicolumn{1}{|c|}{ Type of movement } & Rank \\
\hline \hline 4 & Left turn from approach 3 & 1 \\
\hline 5 & Through traffic on approach 3 & 1 \\
\hline 6 & Right turn from approach 3 & 1 \\
\hline 9 & Right turn from approach 2 & 1 \\
\hline 8 & Through traffic on approach 2 & 2 \\
\hline 7 & Left turn from approach 2 & 2 \\
\hline 3 & Right turn from approach 1 & 2 \\
\hline 1 & Left turn from approach 1 & 3 \\
\hline 2 & Through traffic on approach 1 & 3 \\
\hline 12 & Right turn from approach 4 & 3 \\
\hline 11 & Through traffic on approach 4 & 4 \\
\hline 10 & Left turn from approach 4 & 4 \\
\hline
\end{tabular}

Rank 1 - Movements of Rank 1 include through traffic on the major approach 3, left and right turns from the same approach, as well as right turn from approach 2 (movements 4,5,6,9). Movement 4 (left turn from approach 3) and movement 9 (right turn from approach 2) have the absolute priority, based on the fact that they are on the major road. Movement 5 (through traffic on approach 3) and movement 6 (right turn on approach 3) do not have absolute priority, but they have a higher priority than flows 7 (left turn from approach 2 ) and 8 (through traffic on approach 2 ) in accordance with general traffic rule (priority to the right). While movements 5 and 6 are included in Rank 1 at both types of intersections (standard and non-standard), movements 9 and 4 are included in Rank 1 at non-standard, but in Rank 2 at standard intersections.

- Rank 2 - This Rank includes movement 3 (right turn from approach 2), movement 7 (left turn from approach 2) and movement 8 (through traffic on approach 2). All these movements were included in Rank 1, Rank 3 and Rank 4 at standard TWSC intersection, but none in Rank 2.

- Rank 3 - Movements of this rank include movement 1 (left turn from approach 1), movement 2 (through traffic on approach 1) and movement 12 (right turn from approach 4). None of these movements were included in Rank 3 at a standard TWSC intersection.

- Rank 4 - Rank 4 includes movement 10 (left turn from approach 4) and movement 11 (through traffic on approach 4). Movement 10 is also included in Rank 4, but movement 11 is included in Rank 3 at a standard TWSC intersection.

The analysis of defined ranks at NSUI leads to the conclusion that only 3 movements (5, 6 and 10) are included in the same rank at a standard and a non-standard TWSC intersection.

\subsection{Conflict flow analysis at 4-leg non-standard TWSC intersections}

According to previously defined ranks, conflict flows for all movements have been defined. Movements of Rank 1 have the highest priority and they do not have conflict flows.

For movements of Rank 2, conflict flows are calculated by the following equations:

$$
\begin{aligned}
& V_{c, 3}=V_{4}^{(a)} \\
& V_{c, 7}=V_{4}+V_{5} \\
& V_{c, 8}=V_{4}+V_{5}+V_{6}
\end{aligned}
$$

For movements of Rank 3, conflict flows are calculated by the following equations:

$$
\begin{aligned}
& V_{c, 1}=V_{5}+V_{6}^{(a)}+V_{7}+V_{8} \\
& V_{c, 2}=V_{4}+V_{7}+V_{8}+V_{9}^{(a)} \\
& V_{c, 12}=V_{5}+\frac{1}{2} \cdot V_{6}^{(b)}+V_{7}
\end{aligned}
$$

For movements of Rank 4, conflict flows are calculated by the following equations:

$$
v_{c, 10}=V_{1}+V_{2}+\frac{1}{2} v_{3}^{(b)}+V_{4}+V_{5}+\frac{1}{2} v_{6}^{(b)}+V_{8}+V_{9}^{(a)}
$$


$V_{c, 11}=V_{1}+V_{2}+V_{3}+V_{4}+V_{5}+\frac{1}{2} V_{6}^{(b)}+V_{7}$

Notes:

(a) - if there are two or more receiving lanes, these conflict flows can be excluded from conflict flow calculation;

(b) - if right-turning traffic from the major street is separated by a triangular island and has to comply with a yield or stop sign, $V_{3}$ and $V_{6}$ need not be considered.

\subsection{Capacity analysis at 4-leg non-standard TWSC intersections}

As previously stated, a gap acceptance model can be applied for capacity analysis at NSUI. The basic model for a standard TWSC has to be adjusted to the specific layout of NSUI. The proposed NSUI capacity calculation uses Harders' model [7]. The same model is used for the capacity calculation in HCM2000 and HCM 2010. According to Harders' model, the potential capacity of a minor movement is calculated by the following equation:

$C_{p, x}=V_{c, x} \cdot \frac{e^{-V_{c, x} \cdot t_{c, x / 3600}}}{1-e^{-V_{c, x} \cdot t f, x / 3600}}$

where:

$C_{p, x}$ - potential capacity of movement $X$;

$\mathrm{V}_{c, x}$ - conflicting flow for movement $X$;

$t_{f, x}$ - follow-up headway for movement $X$;

$t_{c, X}$ - critical headway for movement $X$.

A value of the potential capacity represents the ideal capacity of a minor movement. While performing minor movements, the drivers are required to allow vehicles in the major flow and higher rank flows to complete their movements. For this reason, in a real traffic flow, the potential capacity is equal to the movement capacity just for Rank 2 movements, because they have a higher priority than Rank 3 and Rank 4 movements.

For Rank 3 and Rank 4 movements there is traffic impedance, because they must yield not only to the major traffic flows, but also to the conflicting movement, which is of Rank 2. Thus, not all gaps of acceptable length that pass through the intersection will normally be available for use by Rank 3 traffic flows, because some of these gaps are likely to be used by higher ranked traffic.

The magnitude of this impedance depends on the probability that higher rank vehicles will be waiting for an acceptable gap at the same time as vehicles of Rank 3. Impedance value is the probability that Rank 2 flows will be a queue-free state. The probability of the queue-free state is given as:

$P_{0, x}=1-\frac{V_{x}}{C_{m, x}}$ where:

$P_{0, x} \quad$ - probability that conflicting Rank 2 movement will operate in a queue-free state;

$V_{x} \quad$-flow rate for movement $X$;

$C_{m, x}$-movement capacity of movement $X$.

This equation assumes that the analysed movement has an exclusive lane. In the situation where a left-turn lane is not provided, the major street through and right turn traffic could be delayed by left-turning vehicles waiting for an acceptable gap. For this case, the equation becomes:

$P_{0, x}^{*}=1-\frac{1-P_{0, x}}{1-\left(\frac{V_{i 1}}{1,700}+\frac{V_{i 2}}{1,700}\right)}$

where:

$P_{0, x}^{*}$ - probability of queue-free state for a shared lane;

$P_{0, x}$ - probability of queue-free state for movement

$X$ assuming an exclusive left-turn lane on the major street;

$V_{i 1}$ - major-street flow rate 1 in a shared lane with flow $X$;

$V_{i 2}$-major-street flow rate 2 in a shared lane with flow $X$.

\subsubsection{Capacity calculation of Rank 1 movements}

Rank 1 movements have the absolute priority in crossing through the centre of the intersection and they should cross without any delays. For that reason, it is proposed that capacity of Rank 1 movements is calculated according to equations for a saturated flow calculation in one traffic lane for protected phasing at signalised intersections [18].

\subsubsection{Capacity calculation of Rank 2 movements}

For Rank 2 movements (labelled j) there are no impedance effects, and so the movement capacity of all Rank 2 movements is equal to the value of the potential capacity:

$C_{m, j}=C_{p, j}$

where:

$C_{m, j}$-movement capacity of Rank 2 movements;

$C_{p, j}$-potential capacity of Rank 2 movements.

\subsubsection{Capacity calculation of Rank 3 movements}

Vehicles making Rank 3 movements (labelled $k$ ) have to allow all vehicles from higher ranked movements (Rank 1 and Rank 2) to pass, before they finish their movement. When Rank 2 flows become congested, they can operate in a queue state. In this case, the first free gap will be used by a Rank 2 vehicle, rather than a Rank 3 vehicle. That is why vehicles from Rank 3 have fewer available gaps for their movements. This is called vehicle impedance for Rank 3 movements $[5,6]$. Because of vehicle impedance, the capacity of 
Rank 3 movements is calculated according to the following equation:

$C_{m, k}=C_{p, k} \cdot f_{k}$

where:

$C_{m, k}$-movement capacity of Rank 3 movements;

$C_{p, k}$ - potential capacity of Rank 3 movements;

$f_{k} \quad$-capacity adjustment factor for Rank 3 movements.

Capacity adjustment factor for Rank 3 movements is calculated as a product of probabilities that Rank 2 manoeuvres will operate in a queue-free state.

$f_{k}=\prod_{j} P_{0, j}$

where:

$P_{0, j}$ - probability of queue-free state for Rank 2 movements.

In order to calculate the capacity of Rank 3 movements, it is necessary to define capacity adjustment factors.

The capacity adjustment factor for movement 1 (left turn from approach 1) and movement 2 (through movement on approach 1 ) is calculated for queue-free state in flows 7 and 8 . In that case, the equation for the calculation of capacity adjustment factor for movement 1 is:

$f_{1}=f_{2}=P_{0,7} \cdot P_{0,8}$

The capacity adjustment factor for movement 12 (right turn from approach 4) is calculated for a queuefree state only for flow 7 . The equation for the calculation of the adjustment factor for movement 12 is:

$f_{12}=P_{0,7}$

\subsubsection{Capacity calculation of Rank 4 movements}

Movements of Rank 4 (labelled I) are the most complex movements at any TWSC intersection, because they are at the bottom of the movement hierarchy (under Ranks 1, 2 and 3). In order to get a free gap for Rank 4 movement, all vehicles at the intersection have to finish their movements. The capacity of Rank 4 movement is calculated according to the following equation:

$C_{m, l}=C_{p, l} \cdot f_{l}$

where:

$C_{m, l}$-movement capacity of Rank 4 movements;

$C_{p, 1}$-potential capacity of Rank 4 movements;

$f_{l} \quad$-capacity adjustment factor for Rank 4 movements.

Capacity adjustment factor for Rank 4 movements is calculated according to the following equation:

$f_{l}=p^{\prime} \cdot P_{0, j}$

where: $p^{\prime} \quad$-adjustment factor for higher rank minor movements conflicting with Rank 4 movements;

$P_{0, j}$ - probability that Rank 2 right turn will operate in a queue-free state.

Adjustment factor $p^{\prime}$ is calculated according to the following equation:

$p^{\prime}=0.65 \cdot p^{\prime \prime}-\frac{p^{\prime \prime}}{p^{\prime \prime}+3}+0.6 \cdot \sqrt{p^{\prime \prime}}$

where:

$p^{\prime \prime}=P_{0, j} \cdot P_{0, k}$;

$P_{0, j}$-probability that Rank 2 movements, conflicting Rank 4 movement will operate in a queue-free state;

$P_{0, k}$ - probability that Rank 3 movements, conflicting Rank 4 movement will operate in a queue-free state.

\section{Capacity adjustment factor for movement 11}

Movement 11 (through traffic on approach 4) is in conflict with Rank 2 movements (3 and 7) and Rank 3 movements ( 1 and 2). According to the previously defined procedure, the capacity adjustment factor is calculated according to the following equation:

$f_{11}=p_{11}^{\prime} \cdot P_{0,3}$

Value of $p_{11}$ as an input data for calculation of adjustment factor $p_{11}$ is:

$p_{11}=P_{0,7} \cdot P_{0,1} \cdot P_{0,2}$

\section{Capacity adjustment factor for movement 10}

Movement 10 (left turn from approach 4) is in conflict with Rank 2 movements ( 7 and 8 ) and Rank 3 movements (1 and 2). According to the previously defined procedure, the capacity adjustment factor is calculated according to the following equation:

$f_{10}=p_{10}^{\prime}$

Adjustment factor $p_{10}^{\prime}$ is calculated according to Equation 19, where:

$p_{10}=P_{0,7} \cdot P_{0,8} \cdot P_{0,1} \cdot P_{0,2}$

\section{CONCLUSIONS}

Non-standard TWSC intersections are a very common type of intersection in countries with an inherited street network. These intersections are often an optimal solution where left/right turns are intensive, because they have a priority road which bends at the centre of the intersection.

Until now, these intersections had not been a point of interest for researchers, and they had not been analysed in the field of capacity analysis. The fact is that non-standard TWSC intersections are a part of street network with a high traffic volume, so it is necessary to 
know their capacity and the level of service. Any standard TWSC can be transformed into a non-standard TWSC by changing the position of STOP or YIELD signs, or vice versa. For that reason, a gap acceptance model for capacity analysis can be applied at non-standard TWSC intersections, but because of different approach layouts, it has to be adjusted for non-standard TWSC intersections.

This paper analyses 4-leg non-standard TWSC intersections in order to define the procedure for capacity and LOS analysis. For procedure development, all needed major and minor movements have been defined, as well as their spatial orientation at the intersection. Also, movement ranks have been defined, as well as procedures for conflict flow calculation and parameters for Rank 3 and Rank 4 capacity adjustment factors.

The results of the analyses show that non-standard TWSC intersections have unique major and minor movements, significantly different from movements at standard TWSC intersections. Conflict flow rates are also significantly different from standard TWSC intersections, not only in value, but also in the way of calculation. The number and type of minor manoeuvres at non-standard TWSC intersection is twice those of standard TWSC intersection.

In this paper, 3-leg non-standard TWSC intersections have not been analysed. A preliminary analysis shows that they have some specificities regarding their layout, and the procedure defined for 4-leg intersections cannot be used for 3-leg NSUI. Further research studies should define procedures for capacity analysis at 3-leg NSUI and give recommendations for base values of critical headway and follow-up headways at all types of non-standard TWSC intersections (3-leg and 4-leg).

Dr VUK BOGDANOVIĆ1
E-mail: vuk@uns.ac.rs
Dr NENAD RUŠKIĆ1
E-mail: nruskic@uns.ac.rs
Dr VALENTINA BASARIĆ ${ }^{1}$
E-mail: plast@uns.ac.rs
Dr ILIJA TANACKOV ${ }^{1}$
E-mail: ilijat@uns.ac.rs
${ }^{1}$ Univerzitet u Novom Sadu, Fakultet tehničkih nauka
Departman za saobraćaj, Trg Dositeja Obradovića 6,
21000 Novi Sad, Srbija

\section{PROCEDURA ZA PRORAČUN KAPACITETA ČETVO- ROKRAKIH NESTANDARDNIH NESIGNALISANIH RASKRSNICA}

\section{SAŽETAK}

Procedure za proračun kapaciteta nesignalisanih raskrsnica pojavile su se u literaturi '70 godina prošlog veka. Pored standardnih nesignalisanih raskrsnica postoje $i$ nestandardne nesignalisane raskrsnice. Glavna osobina ovih raskrsnica je da se dva prioritetna pravca ne nalaze jedan naspram drugog, već jedan pored drugog. Zbog nestandardnog prostornog rasporeda glavnih $i$ sporednih prilaza na nestandardnim nesignalisanim raskrsnicama postoje jedinstveni glavni $i$ sporedni manevri. Iz tog razloga se na nestandarnim nesignalisanim raskrnsicama ne može primeniti procedura koje se koristi za analizu kapaciteta kod standardnih nesignalisanih raskrsnica. U okviru ovog rada definisana je procedura za analizu kapaciteta nestandardnih nesignalisanih raskrsnica sa novim modelom rangova kretanja za glavne i sporedne manevre, postupak utvrđivanja vrednosti konfliktnih tokova, kao i postupak za proračun potencijalnog $i$ merodavnog kapaciteta u skladu sa prostornim rasporedom glavnih i sporednih prilaza.

\section{KLUUČNE REČI}

kapacitet; prioriet; prihvatljivi intervali; konfliktni tok; nivo usluge

\section{REFERENCES}

[1] MUTCD. Manual on Uniform Traffic Control Devices for Streets and Highways. Washington D.C: U. S. Department of Transportation Federal Highway Administration; 1988.

[2] MUTCD. Manual on Uniform Traffic Control Devices for Streets and Highways. Washington D.C: U. S. Department of Transportation Federal Highway Administration; 2009.

[3] Department of Transport and Main Roads. Guide to Modified Intersection Signs. Queensland; 2009.

[4] Bogdanović V, Ruškić N, Kulović M, Han LD. Toward a Capacity Analysis Procedure for Nonstandard TwoWay Stop-Controlled Intersections. Transportation Research Record: Journal of the Transportation Research Board. 2014;2395: 132-138.

[5] Transportation Research Board of The National Research Council. Highway Capacity Manual - Chapter 17 - Unsignalised Intersections. Washington D.C; 2000.

[6] Transportation Research Board of The National Research Council. Highway Capacity Manual - Chapter 19 - Two-Way Stop-Controlled Intersections. Washington D.C.; 2010.

[7] Harders J. Die Leistungsfähigkeit nicht signalregelter städtischer Verkshrsknoten [Capacity of unsignalised urban intersections]. Bonn: Bundesminister für Verkehr; 1968.

[8] Siegloch W. Die Leistungsermittlung an Knotenpunkten ohne Lichtsignalanlagen (Capacity calculations at unsignalised intersections). Series Strassenbau und Strassenverkehrstechnik; 1973.

[9] ADAC. Traffic signs and signals in Germany. München: Allgemeiner Deutscher Automobil-Club e.V; 2010.

[10] FINRA. Road signs and other devices of traffic control in Finland: Finnish road administration; 2004.

[11] Road Safety Authority (Ireland). Rules of the Road. Dublin: Road safety; 2013.

[12] Road Research Laboratory. Research on Road Traffic, London: Department of Scientific and Industrial Research; 1965.

[13] Transportation Research Board of the National Research Council. Highway Capacity Manual. Washington D.C; 1965. 
[14] Transportation Research Board of the National Research Council. Highway Capacity Manual. Washington D.C; 1985.

[15] Transportation Research Board of the National Research Council. Highway Capacity Manual. Washington D.C; 1994.

[16] Gattis JL, Low ST. Gap Acceptance at Nonstandard Stop-controlled Intersections. Springfield, VA: National Technical Information Service; 1998.

[17] Ruškić N. Capacity analysis of non-standard unsignalised intersections [PhD thesis]. Novi Sad, Serbia: University of Novi Sad, Faculty of Technical Sciences; 2013.

[18] Transportation Research Board of The National Research Council. Highway Capacity Manual. Chapter 16 - Signalised Intersections. Washington D.C; 2000.

[19] Ministry of Infrastructure. Pravilnik o saobraćajnoj signalisaciji (Serbian traffic signs manual). Belgrade, Serbia: Government of Republic of Serbia; 2010.

[20] Rakha H, Sadek S, Zohdy I. Modelling Differences in Driver Left-Turn Gap Acceptance Behavior Using Bayesian and Bootstrap Approaches. Procedia Social and Behavioral Sciences. 2011;16:739-750.

[21] Hewitt R. Measuring critical gap. Transportation science. 1983;17(1): 87-109.
[22] Akçelik R. A Review of Gap-Acceptance Capacity Models. Proceedings of the $29^{\text {th }}$ Conference of Australian Institutes of Transport Research CAITR 2007, 5-7 Dec 2007, Adelaide, Australia; 2007. 25 p.

[23] Li H, Tian Z, Deng W. Capacity of TWSC Intersection with Multilane Approaches. Procedia Social and Behavioral Sciences. 2011;16: 664-675.

[24] Miaomiao L, Guangquan L, Yunpeng W, Zhe Z. Analyzing drivers' crossing decisions at unsignalised intersections in China. Transportation Research Part F: Traffic Psychology and Behaviour. 2014;24: 244-255.

[25] Miaomiao L, Guangquan L, Yunpeng W, Ying W, Zhe Z. Preempt or yield? An analysis of driver's dynamic decision making at unsignalised intersections by classification tree. Safety Science. 2014;65: 36-44.

[26] Miaomiao L, Yongsheng C, Guangquan L, Yunpeng W. Modeling crossing behavior of drivers at unsignalised intersections with consideration of risk perception. Transportation Research Part F: Traffic Psychology and Behaviour. 2017;45: 14-26.

[27] Praveen D, Naga Sai Baba A, Kameswara Rao M. Delay modelling at urban uncontrolled intersections. International Journal of Advance Engineering and Research Development. 2016;3(2): 112-118. 